\title{
Structure of Ice III
}

\author{
By Barclay Kamb and Anand Prakash \\ California Institute of Technology*, Pasadena, California, U.S.A.
}

(Received 22 November 1967)

\begin{abstract}
Ice III, least dense of the high pressure forms of ice $\left(\varrho_{c}=1.160 \mathrm{~g} . \mathrm{cm}^{-3}\right.$ at $\left.-175^{\circ} \mathrm{C}, 1 \mathrm{~atm}\right)$, has a tetragonal structure $\left(P 4_{1} 2{ }_{1} 2, a=6.73, c=6.83 \AA\right)$ involving a tetrahedrally linked H-bond framework with mean bond length $2.775 \AA$. The increase in density relative to ice I $(0.94 \mathrm{g.cm}-3)$ is accomplished by distortions from ideal tetrahedral coordination which allow two or three non-bonded neighbors to approach each water molecule to distances of about $3.6 \AA$, much closer than the corresponding distance of $4.50 \AA$ in ice I. The ice III framework has numerous five-ring connections, whereas only six-rings (and larger) are present in ice I; it is topologically analogous to the framework in silica- $\mathrm{K}$, but corresponding structural parameters in the two analogs differ markedly. One $\mathrm{O} \cdots \mathrm{O} \cdots \mathrm{O}$ coordination angle in ice III has the extraordinarily large value $143^{\circ}$. This should cause a marked destabilization of the water molecule orientation presented into this angle, and could lead to proton ordering at lower temperatures, for which there is some independent physical evidence. The X-ray data refine to $R=0.051$ for a half-hydrogen (disordered) model, and to $R=0.057$ for one of the four full-hydrogen (ordered) proton arrangements possible in $P 4_{1} 2_{1} 2$. Although the difference between these results is not statistically significant, the crystallographic evidence is weighted in favor of the half-hydrogen model. The protonordered arrangement admitted as an alternative by the X-ray data utilizes the most favorable watermolecule orientations available in the structure.
\end{abstract}

\section{Introduction}

Ice III is the most accessible of the high-pressure forms of ice; it is made from ice I by raising the pressure to above 2070 bars, at temperatures below the ice Iice III-liquid triple point at $-22 \cdot 0{ }^{\circ} \mathrm{C}$. Its structure, reported in preliminary form by Kamb \& Datta (1960), was the first of the high pressure ice structures to be determined. It was of interest in showing that tetrahedral coordination of the water molecules is retained (though with distortion), and that the structural analogy with $\mathrm{SiO}_{2}$ polymorphs extends into the domain of the dense ice phases.

A refinement of the ice III structure was carried out by Kamb \& Datta in 1960 (unpublished), using X-ray intensities derived mostly from rotation photographs, a procedure followed because we thought at that time that crystals of ice III were unstable under X-irradiation. We have subsequently restudied this question in an effort to get better X-ray data, and we find that the supposed X-ray instability, which did not appear in any of the other quenched ice phases, does not in fact exist for ice III either. With our new set of intensity data we are now able to carry out a more satisfactory refinement and interpretation of the structure than was possible previously.

\section{Experimental procedure}

The method used to prepare and quench the highpressure ice samples has been described (Kamb \& Datta, 1960; Kamb, 1965a). Ice III was made by cool-

\footnotetext{
* Division of Geological Sciences, Contribution No. 1491.
}

ing a water sample, at 3 kilobars pressure, from room temperature to $-40^{\circ} \mathrm{C}$, at a cooling rate of about $\frac{1}{2}{ }^{\circ} \mathrm{C}$ per minute. The sample was held at $-40^{\circ} \mathrm{C}$ for half an hour, and was then quenched in liquid nitrogen. Individual glass capillaries $0.3-0.6 \mathrm{~mm}$ in diameter, containing the ice samples, were examined at a temperature of $-175^{\circ} \mathrm{C}$ on the precession camera. Out of 120 capillaries tested, only one contained a single crystal well suited for collecting diffraction data. This crystal was used to obtain all of the intensity data reported here.

The identification of the samples as ice III follows from their consistent formation under the appropriate $P, T$ conditions outlined in the $\mathrm{H}_{2} \mathrm{O}$ phase diagram (Bridgman, 1912). Although the quenching must be carried through the ice II field, the ice III samples do not transform to ice II on quenching. The distinction from ice II is established by forming ice II initially from ice I at $-75^{\circ} \mathrm{C}$, as described by Bridgman (1912, p.489). Some initial difficulty was caused by the fact that, as noted previously (Kamb \& Datta, 1960), the X-ray powder data reported earlier for ice II by McFarlan (1936a) are more nearly appropriate to ice III, and the data reported for ice III (McFarlan, 1936b) do not correspond to any of the high pressure forms of ice that we have observed. Identification of the samples as ice III was confirmed by Bertie, Calvert \& Whalley (1963), who published powder data in general agreement with the data from our samples.

\section{X-ray data}

Ice III is tetragonal, with cell size (at $1 \mathrm{~atm} .,-175^{\circ} \mathrm{C}$ ) $a=6.73 \pm 0.01, c=6.83 \pm 0.01 \AA$. (Lattice constants are 
based on assumed wavelengths $\lambda(\mathrm{Cu} K \alpha)=1.542 \AA$, $\lambda($ Mo $K \alpha)=0.7107 \AA$.) The density calculated on the basis of 12 water molecules in this cell is $1.160 \mathrm{~g} . \mathrm{cm}^{-3}$. A density $1.146{\mathrm{~g} . \mathrm{cm}^{-3}}^{-3}$ was measured at 2070 bars and $-22^{\circ} \mathrm{C}$ by Bridgman (1912). Corrected approximately to $-175^{\circ} \mathrm{C}$ by assuming that the measured thermal expansion of ice I (at 0 pressure) (Powell, 1958; Brill \& Tippe, 1967) applies to ice III over this temperature interval, the experimental density of ice III at $2.0 \mathrm{~kb}$ is $1.163 \mathrm{~g} . \mathrm{cm}^{-3}$, only slightly larger than the density calculated from the X-ray data at $0 \mathrm{~kb}$. To some extent this discrepancy may be attributable to the fact that the ice densities measured by Bridgman seem to be consistently low relative to densities calculated from X-ray measurements under pressure (Kamb, Prakash \& Knobler, 1967, Table 1). However, it probably is caused mainly by an abnormally large thermal expansion of ice III over the temperature interval $-60^{\circ} \mathrm{C}$ to $-22^{\circ} \mathrm{C}$, discussed later. Taking account of this abnormal thermal expansion increases the estimated experimental density at $2.0 \mathrm{~kb},-175^{\circ} \mathrm{C}$, to 1.19 g.cm ${ }^{-3}$.

Extinction conditions $00 l$ with $l \neq 4 n$ ( $n$ integral) and $h 00$ with $h \neq 2 n$ define the space group uniquely as $P 4_{1} 2_{1} 2$ (or $P 4_{3} 2_{1} 2$ ).

Three-dimensional diffracted intensity data were collected with Mo $K \alpha$ radiation, by means of precession photographs (zero and upper layers) about the axes [110] and [102], multiple exposures being used to extend the range of intensity measurement. The intensities were estimated visually by comparison with a standard intensity scale, prepared from the same crystal. Corrections for Lorentz and polarization factors were made in the usual way. No absorption corrections were applied.

Intensities from different films were then scaled together by a least-squares method. The standard deviations of individual intensity readings, $\sigma(I)$, were assumed proportional to $I$ in the mid-range of the intensity scale, and the proportionality constant $(0.055$ for axis [110], 0.079 for axis [102]) was evaluated from the least-squares comparison of intensity readings on different films about the same axis. For intensities approaching the lower limit of detection, $\sigma(I)$ was assumed to approach $0.40 I$. From the $\sigma(I)$ values so determined, $\sigma\left(F^{2}\right)$ values were obtained directly by scaling with the $L p$ factor. $F_{o}^{2}$ values from different films were averaged with weighting $1 / \sigma^{2}\left(F^{2}\right)$, and the standard deviations $\sigma\left(F_{o}^{2}\right)$ of the averaged $F_{o}^{2}$ values were calculated from the individual $\sigma\left(F^{2}\right)$ values by the usual propagation-of-error methods.

The data list (Table 1) contains 234 reflections, of which 122 were strong enough to measure, the remainder lying below a known limit.

\section{Refinement of the structure}

Starting from the trial structure found by Kamb \& Datta (1960), a least-squares refinement of oxygen coordinates and isotropic temperature parameters, with hydrogen atoms omitted, converged to a residual $R\left(=\Sigma|| F_{o}|-| F_{c}|| / \Sigma\left|F_{o}\right|\right)$ of 0.089 . A three-dimensional difference synthesis computed at this stage (Fig. 1) shows four low peaks near each oxygen atom, approximately along the nearest-neighbor oxygenoxygen centerlines and about $1.0 \AA$ distant from the oxygen atoms. This suggests a half-hydrogen model for the structure. Hydrogen atoms with population factor $\frac{1}{2}$ were accordingly placed at the positions indicated by the difference map, and oxygen coordinates and thermal motion parameters (now taken anisotropic) were refined a second time. A least-squares refinement of the hydrogen coordinates (positions only; isotropic thermal parameters were assigned the fixed value $B=1.5 \AA^{2}$ ) was then undertaken, and it converged, leading to $R=0.052$ (for observed reflections). Finally, oxygen parameters were again refined, yielding $R=0.051$ (for observed reflections). The refined hydrogen positions are plotted in Fig. 1, for comparison with the peaks in the difference synthesis.

\section{Table 1. Observed and calculated structure factors for ice III}

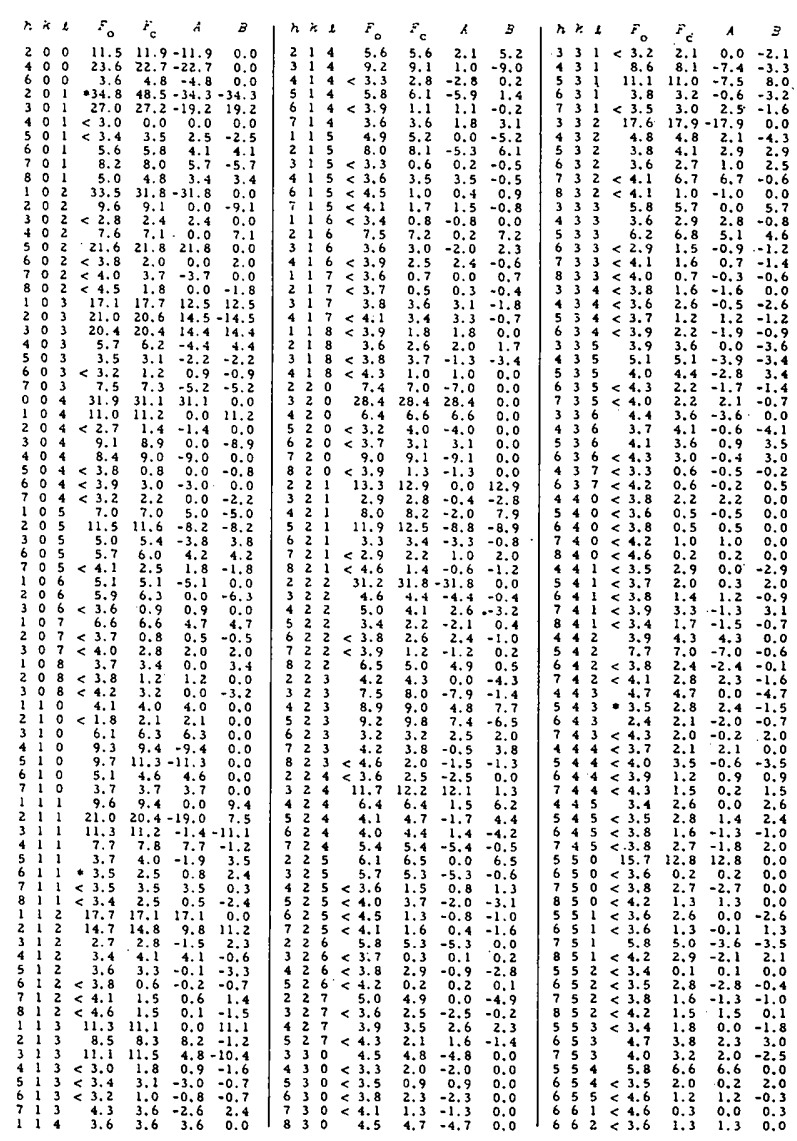

* Indicates reflections given zero weight in the least-squares refinement because of abnormally large measurement uncertainties. 
Scattering factors used in the refinement are those of the International Tables for X-ray Crystallography (1959) for oxygen and of Stewart, Davidson \& Simpson (1965) for hydrogen. Weights $w$ applied to the terms of the least-squares sum $\sum w\left(F_{o}^{2}-F_{c}^{2}\right)^{2}$ were inversely proportional to $\sigma^{2}\left(F_{o}^{2}\right)$, where the standard deviations $\sigma\left(F_{0}^{2}\right)$ for the individual reflections are those estimated in the least-squares processing of the initial intensity data, as described earlier. Final oxygen position coordinate shifts were less than $6 \times 10^{-5}$, well below the

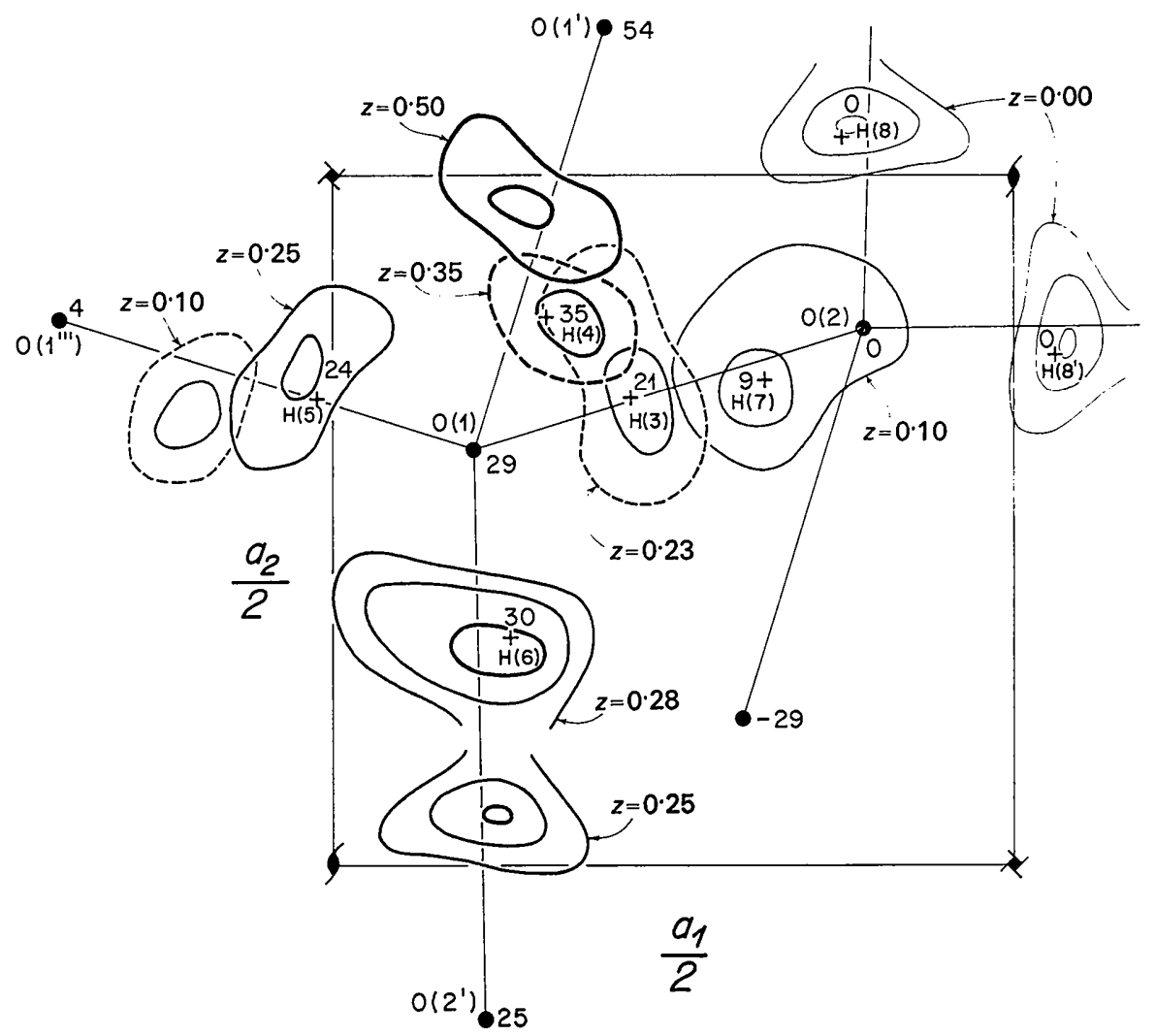

Fig. 1. Portions of sections from a three-dimensional difference synthesis for ice III, seen in projection along the $c$ axis (origin at lower left). The difference synthesis was computed after refinement of oxygen parameters but before inclusion of hydrogen atoms. The sections shown are chosen to pass through the highest positive peaks in the difference density. Solid contours are at intervals of 0.1 e. $\AA^{-3}$, starting with the $0.2 \mathrm{e} . \AA^{-3}$ contour; the $0.1 \mathrm{e} . \AA^{-3}$ contour is dashed where shown. Oxygen positions (dots) are identified and labelled with their approximate $z$ coordinates in hundredths of $c$, and the connecting oxygen-oxygen bond lines are indicated. Crosses locate the hydrogen positions found by least-squares refinement (half-hydrogen model), and are labelled with the refined $z$ coordinates in hundredths of the $c$-axial length, for comparison with the peaks in the difference synthesis.

Table 2. Structure factor residuals for different $\mathrm{H}$ arrangements

$\begin{array}{lllll}\begin{array}{c}\text { Model } \\ \text { No hydrogen }\end{array} & \begin{array}{c}\text { Oxygen* } \\ \text { thermal motion }\end{array} & \begin{array}{l}\text { Hydrogen } \\ \text { Isotropic }\end{array} & \begin{array}{l}\text { None } \\ \text { Nonitions }\end{array} & \begin{array}{l}R \dagger \\ R^{2} \text { ws }\end{array} \\ \text { Ordered } A & \text { Isotropic } & \text { Centerline } & 0.089 & 0.044 \\ \text { Ordered } B & \text { Isotropic } & \text { Centerline } & 0.086 & 0.056 \\ \text { Ordered } C & \text { Isotropic } & \text { Centerline } & 0.089 & 0.093 \\ \text { Ordered } D & \text { Isotropic } & \text { Centerline } & 0.071 & 0.039 \\ \text { Ordered } D & \text { Anisotropic } & \text { Centerline } & 0.067 & 0.026 \\ \text { Ordered } D & \text { Anisotropic } & \text { L.s. refined } & 0.057 & 0.018 \\ \text { Disordered } & \text { Isotropic } & \text { Difference map } & 0.060 & 0.020 \\ \text { Disordered } & \text { Anisotropic } & \text { Difference map } & 0.055 & 0.015 \\ \text { Disordercd } & \text { Anisotropic } & \text { L.s. refined } & 0.051 & 0.0112\end{array}$

* Oxygen coordinates refined by least squares in all models.

$\leftarrow R=\Sigma|| F_{0}|-| F_{c}|||\Sigma| F_{0} \mid$.

$\ddagger R^{2} \mathrm{ws}=\Sigma w\left(F_{o}^{2}-F_{c}^{2}\right)^{2} / \Sigma w F_{0}^{4}$. 
standard deviations of about $4 \times 10^{-4}$ estimated from the (full matrix) least-squares refinement. The final goodness of fit was $1 \cdot 45$.

In an effort to see whether, in spite of the indications of Fig. 1, a full-hydrogen model could account equally well for the X-ray data, the four possible H-bonded, ordered arrangements of water molecules in space group $P 4{ }_{1} 2{ }_{1} 2$ were tested by assuming the protons to lie along the nearest-neighbor oxygen-oxygen centerlines $1.0 \AA$ distant from oxygen. The results are compared in Table 2, where the ordered structures are designated $A$ through $D$. Structure $D$, which gave the best agreement with the X-ray data, was then further refined in the way described above for the half-hydrogen structure, leading to $R=0.057$. The refined hydrogen coordinates, while differing slightly from those of the corresponding positions in the half-hydrogen model, still fall well within the appropriate peaks in the difference synthesis of Fig. 1.

Final parameters for the two refined models are listed in Tables 3 and 4. Observed structure factors are compared in Table 1 with structure factors calculated from the half-hydrogen model; structure factors calculated from full-hydrogen structure $D$ differ only slightly, and are omitted.

\section{Discussion}

The structure of ice III is depicted in Fig. 2. It represents a tetrahedrally linked framework of hydrogen bonds. Each oxygen atom has four near neighbors at distances of $2 \cdot 76-2 \cdot 80 \AA$ (Table $5^{*}$ ), typical of hydrogen bond lengths. Since the next-nearest-neighbor oxygen atoms are all more distant than $3.44 \AA$, there is no ambiguity as to identification of the hydrogen bonds, which are shown diagramatically as rods connecting the oxygen atoms in Fig. 2. The $\mathrm{O}(1)$ atoms form hydrogen-bonded spirals around the $4_{1}$ screw axes, and these spirals are connected to one another via the $\mathrm{O}(2)$ atoms, each of which links four spirals together.

* Bond lengths for both the half-hydrogen and full-hydrogen models are listed in Table 5 , but the difference between them is only marginally significant and has no effect on the discussion here. Unless otherwise specified, bond lengths and angles quoted are for the half-hydrogen model.
Table 4. Thermal parameters for ice III

Isotropic $B$, and principal axes of anisotropic thermal motion ellipsoids $B_{i}$, are in $\AA^{2}$ (' $B$ units'). $B$ was obtained by isotropic refinement of oxygen after inclusion of hydrogen atoms. Anisotropic temperature factor has the form

$$
\exp \left[-10^{-4} \cdot\left(\beta_{11} h^{2}+\beta_{22} k^{2}+\beta_{33} l^{2}+\beta_{12} h k+\beta_{13} h l+\beta_{23} k l\right)\right] \text {. }
$$

e.s.d. in last decimal place given in parenthesis.

\begin{tabular}{cc}
\multicolumn{2}{c}{ Half-H model } \\
$\mathrm{O}(1)$ & $\mathrm{O}(2)$ \\
$2 \cdot 48(10)$ & $2 \cdot 51(11)$ \\
$2 \cdot 7(3)$ & $3 \cdot 4(3)$ \\
$2 \cdot 5(3)$ & $2 \cdot 6(3)$ \\
$2 \cdot 3(3)$ & $1 \cdot 5(3)$ \\
$137(9)$ & $117(7)$ \\
$142(11)$ & $117(7)$ \\
$129(6)$ & $174(10)$ \\
$0(13)$ & $-69(17)$ \\
$15(16)$ & $-23(13)$ \\
$16(13)$ & $23(13)$
\end{tabular}

\begin{tabular}{cc}
\multicolumn{2}{c}{ Full-H } \\
$\mathrm{O}(1)$ & $\mathrm{O}(2)$ \\
$2 \cdot 35(11)$ & $2 \cdot 51(13)$ \\
$3 \cdot 0(3)$ & $3 \cdot 6(3)$ \\
$2 \cdot 6(3)$ & $2 \cdot 6(3)$ \\
$1 \cdot 6(3)$ & $1 \cdot 3(3)$ \\
$119(9)$ & $134(7)$ \\
$141(12)$ & $134(7)$ \\
$137(7)$ & $139(10)$ \\
$29(14)$ & $-122(19)$ \\
$-65(17)$ & $-13(14)$ \\
$15(14)$ & $13(14)$
\end{tabular}

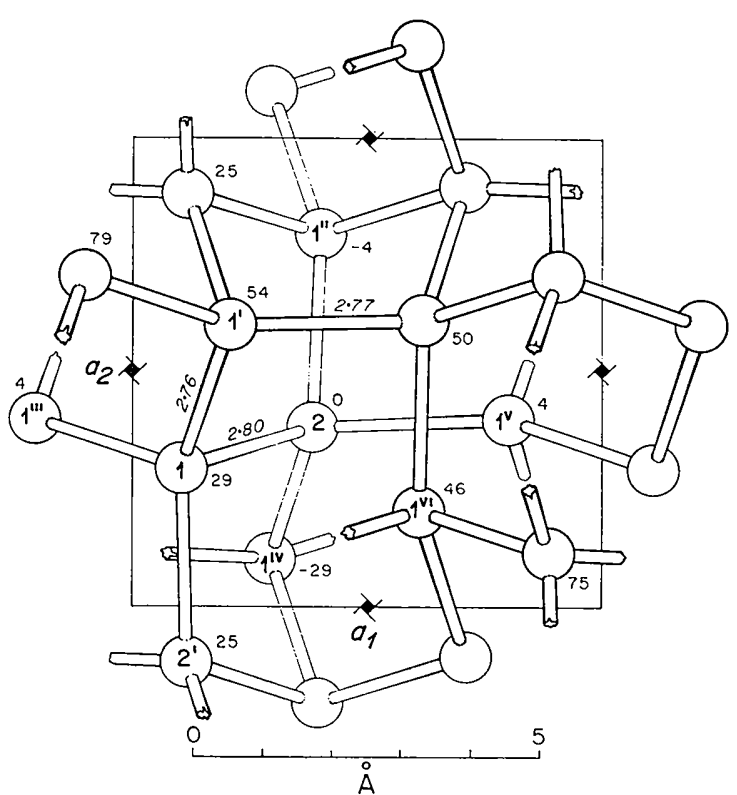

Fig. 2. Structure of ice III, as viewed along the $c$ axis. Oxygen atoms are shown as balls, and the connecting $\mathrm{H}$-bonds as rods, with bond lengths $(\AA)$ labelled. Hydrogen atoms are not shown, but can be located by reference to Fig. 1. Numbering of oxygen atoms corresponds to the usage in Tables 5 and 6 . Oxygen $z$ coordinates are given in hundredths of the $c$-axial length. Coordinate origin is at lower left.

Table 3. Atomic coordinates for ice III

e.s.d. in last decimal place given in parenthesis.

Half-hydrogen model

\begin{tabular}{ccccc}
\cline { 3 - 5 } Atom & Position & $x$ & $y$ & \multicolumn{1}{c}{$y$} \\
O(1) & $8(b)$ & $0 \cdot 1063(4)$ & $0.2993(4)$ & $0.2865(4)$ \\
O(2) & $4(a)$ & $0.3895(4)$ & $0.3895(4)$ & 0 \\
H(3) & $8(b)$ & $0.217(10)$ & $0.341(11)$ & $0.206(17)$ \\
H(4) & $8(b)$ & $0.154(11)$ & $0.395(12)$ & $0.341(14)$ \\
H(5) & $8(b)$ & $-0.018(14)$ & $0.335(9)$ & $0.233(13)$ \\
H(6) & $8(b)$ & $0.129(10)$ & $0.166(14)$ & $0.301(15)$ \\
H(7) & $8(b)$ & $0.319(13)$ & $0.350(13)$ & $0.086(13)$ \\
H(8) & $8(b)$ & $0.374(7)$ & $0.524(14)$ & $-0.009(11)$
\end{tabular}

Full-hydrogen model $D$

\begin{tabular}{ccc}
\hline$x$ & $y$ & $z$ \\
$0.1096(4)$ & $0.3016(4)$ & $0.2873(5)$ \\
$0.3932(4)$ & $0.3932(4)$ & 0 \\
- & - & - \\
- & $\overline{-}$ & $\overline{-}$ \\
$-0.003(8)$ & $0.322(4)$ & $0.215(6)$ \\
$0.107(5)$ & $0.162(5)$ & $0.288(7)$ \\
$0.296(5)$ & $0.354(5)$ & $0.095(6)$ \\
- & - & -
\end{tabular}


Table 5. Interatomic distances $(\AA)$

Distances uncorrected for thermal motion.

\begin{tabular}{|c|c|c|}
\hline $\begin{array}{c}\text { Model: } \\
\text { H-bonds }( \pm 0.005 \AA)\end{array}$ & Half-H & $D$ (full-H \\
\hline $\begin{array}{l}O(1)-O\left(1^{\prime}\right) \\
O(1)-O(2) \\
O\left(1^{\prime \prime}\right)-O(2)\end{array}$ & $\begin{array}{l}2 \cdot 757 \\
2 \cdot 797 \\
2 \cdot 767\end{array}$ & $\begin{array}{l}2 \cdot 747 \\
2 \cdot 806 \\
2 \cdot 763\end{array}$ \\
\hline \multicolumn{3}{|c|}{ Shortest non-bonded distances $( \pm 0.005)$} \\
\hline $\begin{array}{l}O\left(1^{v}\right)-O\left(1^{v i}\right) \\
O(1)-O\left(1^{v i}\right) \\
O(2)-O\left(1^{v i}\right)\end{array}$ & $\begin{array}{l}3 \cdot 446 \\
3 \cdot 637 \\
3 \cdot 711\end{array}$ & $\begin{array}{l}3 \cdot 432 \\
3 \cdot 640 \\
3 \cdot 720\end{array}$ \\
\hline \multicolumn{3}{|c|}{ O-H distances $( \pm 0.08 \AA)$} \\
\hline $\begin{array}{l}\mathrm{O}(1)-\mathrm{H}(3) \\
\mathrm{O}(1)-\mathrm{H}(4) \\
\mathrm{O}(1)-\mathrm{H}(5) \\
\mathrm{O}(1)-\mathrm{H}(6) \\
\mathrm{O}(2)-\mathrm{H}(7) \\
\mathrm{O}(2)-\mathrm{H}(8)\end{array}$ & $\begin{array}{l}0.96 \\
0.81 \\
0.96 \\
0.91 \\
0.80 \\
0.91\end{array}$ & $\begin{array}{r}- \\
0 . \overline{92} \\
0.96 \\
0.98 \\
-\end{array}$ \\
\hline
\end{tabular}

The ice III structure can be compared topologically with ice I in terms of the ring connectivities of the two frameworks. In ice I and Ic there are abundant sixring connections, each water molecule being a member of 12 six-rings, and there are no smaller rings. In ice III, five-rings occur: each $O(1)$ is a member of two five-rings, and each $\mathrm{O}(2)$ of four five-rings. Ice $\mathrm{V}$, somewhat denser than ice III, contains some four-rings, and four-rings are numerous in ice VI (Kamb, Prakash \& Knobler, 1967; Kamb, 1965a). A decrease in ring size is not, however, a necessary feature of increased ice density, as shown by the fact that the smallest rings in ices II and VII are six-rings (Kamb, 1964; Kamb \& Davis, 1964). Three-rings do not occur in any known ice structure.

The increase in density of ice III over that of ice I is accomplished not by an increase in nearest-neighbor coordination number or by a decrease in bond length, but instead by a decrease in next-nearest neighbor distance, from the $4.50 \AA$ in ice I to about $3.6 \AA$ in ice III. $\mathrm{O}(1)$ atoms have three oxygen neighbors at $3 \cdot 44-3 \cdot 71 \AA$, and $\mathrm{O}(2)$ atoms have two neighbors at $3.71 \AA$ (Table 5). Unlike in ice I, where the oxygen atoms at $4.50 \AA$ are next-nearest neighbors both in the sense of distance and in the sense of connectivity of the bond network, in ice III the neighbors at about $3.6 \AA$ are third- or fourth-neighbors as counted outward along the bonds. This 'doubling back' of the bond framework is a way of introducing near neighbors (and hence of increasing the density) without requiring excessive bending of the hydrogen bonds.

The bending of the bonds, as measured by the distortion of the water molecule coordination from ideal tetrahedral, is shown by the $\mathrm{O} \cdots \mathrm{O} \cdots \mathrm{O}$ bond angles in Table 6. The average bond angle remains near $109.5^{\circ}$, of course, but the r.m.s. departure of the bond angles from this value is $16.4^{\circ}$. All angles lie in the range 10$) \cdot 5 \pm 20^{\circ}$, with the conspicuous exception of the angle $\mathrm{O}\left(1^{\prime}\right)-\mathrm{O}(1)-\mathrm{O}\left(2^{\prime}\right)$, amounting to $143^{\circ} 3^{\circ}$. This extraordinary angle has the greatest departure from $109.5^{\circ}$ or from $104.5^{\circ}$ of any $\mathrm{O} \cdots \mathrm{O} \cdots \mathrm{O}$ bond angle in any of the known ice structures. The departure is approached only by the $76^{\circ}$ bond angle in ice VI (Kamb, 1964). The average distortion of tetrahedral coordination in ice III, as measured by the r.m.s. bondangle deviation from $109.5^{\circ}$, is the least of any of the dense forms of ice (Kamb, 1968); it is less than that of ice II (r.m.s. deviation $17^{\circ}$ ) by only a slim margin if the $143.3^{\circ}$ angle is included, but by a wide margin if this angle is omitted in the comparison.

\section{Table 6. $\mathrm{O} \cdots \mathrm{O} \cdots \mathrm{O}$ bond angles and corresponding $\mathrm{H}-\mathrm{O}-\mathrm{H}$ angles (for half-hydrogen model)}

$\begin{array}{lclr}\mathrm{O}\left(1^{\prime}\right)-\mathrm{O}(1)-\mathrm{O}\left(1^{\prime \prime \prime}\right) & 112 \cdot 5^{\circ} & \mathrm{H}(4)-\mathrm{O}(1)-\mathrm{H}(5) & 109^{\circ} \\ \mathrm{O}\left(1^{\prime}\right)-\mathrm{O}(1)-\mathrm{O}(2) & 96 \cdot 5 & \mathrm{H}(3)-\mathrm{O}(1)-\mathrm{H}(4) & 74 \\ \mathrm{O}\left(1^{\prime}\right)-\mathrm{O}(1)-\mathrm{O}\left(2^{\prime}\right) & 143 \cdot 2 & \mathrm{H}(4)-\mathrm{O}(1)-\mathrm{H}(6) & 132 \\ \mathrm{O}\left(1^{\prime \prime \prime}\right)-\mathrm{O}(1)-\mathrm{O}(2) & 91 \cdot 6 & \mathrm{H}(3)-\mathrm{O}(1)-\mathrm{H}(5) & 113 \\ \mathrm{O}\left(1^{\prime \prime \prime}\right)-\mathrm{O}(1)-\mathrm{O}\left(2^{\prime}\right) & 100 \cdot 4 \dagger & \mathrm{H}(5)-\mathrm{O}(1)-\mathrm{H}(6) & 116 \\ \mathrm{O}(2)-\mathrm{O}(1)-\mathrm{O}\left(2^{\prime}\right) & 98 \cdot 5 & \mathrm{H}(3)-\mathrm{O}(1)-\mathrm{H}(6) & 103 \\ \mathrm{O}(1)-\mathrm{O}(2)-\mathrm{O}\left(1^{\prime \prime}\right) & 106 \cdot 6 & \mathrm{H}(7)-\mathrm{O}(2)-\mathrm{H}(8) & 108 \\ \mathrm{O}(1)-\mathrm{O}(2)-\mathrm{O}\left(1^{\mathrm{iv}}\right) & 101 \cdot 1 \dagger & \mathrm{H}(7)-\mathrm{O}(2)-\mathrm{H}\left(7^{\prime}\right) & 98 \\ \mathrm{O}(1)-\mathrm{O}(2)-\mathrm{O}\left(1^{\mathrm{v}}\right) & 128 \cdot 1 & \mathrm{H}(7)-\mathrm{O}(2)-\mathrm{H}\left(8^{\prime}\right) & 120 \\ \mathrm{O}\left(1^{\prime \prime}\right)-\mathrm{O}(2)-\mathrm{O}\left(1^{\mathrm{v}}\right) & 89 \cdot 5 & \mathrm{H}(8)-\mathrm{O}(2)-\mathrm{H}\left(8^{\prime}\right) & 104 \\ & & \text { Estimated } & \\ \text { Estimated standard } & & \text { standard } & \\ \text { deviation } & 0.2 & \text { deviation } & 8 \\ & & \end{array}$

The topology of the ice III structure is the same as that of one of the polymorphs of $\mathrm{SiO}_{2}$, silica-K ('keatite') (Shropshire, Keat \& Vaughan, 1959), silicon in the $\mathrm{SiO}_{2}$ structure playing the role of oxygen in the ice structure, and the $\mathrm{Si}-\mathrm{O}-\mathrm{Si}$ bridges being topologically equivalent to the hydrogen bonds. In view of the well known structural analogy between ice I and tridymite, and between ice Ic and cristobalite, the occurrence of analogous structures among the denser phases was to be expected, but ice III proves to be the only such straightforward silica analog among the dense ice structures so far found. There is, however, a further example among the less dense phases, the analogy between the ice-like $12 \AA$ clathrate hydrate structure and the clathrate silica mineral melanophlogite (Kamb, 1965a).

Although ice III and silica-K are structural analogs, there are marked differences in the detailed geometry of the two structures. The axial ratio $c / a$ is rather different, the atomic coordinates of corresponding atoms show marked differences, and the effective packing densities (relative to the analog structures ice $I$ and tridymite) differ notably (Table 7). In spite of these differences, the bond or bridge lengths within each structure remain nearly equal (Table 5). This indicates that the geometry of the structure is such that there is a degree of freedom for adjustment of bond angles, without marked change in bond lengths. The detailed differences between ice III and silica-K are therefore probably due to differences in the bond-bending force constants for the two types of tetrahedral bond linkage. 
The angles $\mathrm{Si}-\mathrm{Si}-\mathrm{Si}$ in silica-K differ from the corresponding angles $\mathrm{O} \cdots \mathrm{O} \cdots \mathrm{O}$ in ice III by up to $9^{\circ}$; there is no obvious pattern in the angle changes, except that the $1^{\prime}-1-2^{\prime}$ angle of $143.3^{\circ}$ in ice III is decreased by $8^{\circ}$ in silica-K. Because of the normal bending of the Si-O-Si linkage, it is, of course, to be expected that the angular relations for $\mathrm{Si}-\mathrm{Si}-\mathrm{Si}$ angles in silica phases may be different from those for the $\mathrm{O} \cdots \mathrm{O} \cdots \mathrm{O}$ angles in ice phases.

\section{Table 7. Comparison of ice III and silica $\mathrm{K}$}

The reference density $Q_{\mathrm{I}}$ is that of ice $\mathrm{I}$ for $\mathrm{H}_{2} \mathrm{O}$ and of tridymite for $\mathrm{SiO}_{2}$.

$\mathrm{T}$ refers to oxygen atoms in ice III and to silicon atoms in silica $\mathrm{K}$.

$\begin{array}{lll} & \text { Ice III } & \text { Silica K } \\ \text { Q/ } \varrho_{\mathrm{I}} & 1.296 & 1 \cdot 11 \\ c / a & 1 \cdot 015 & 1 \cdot 155 \\ \mathrm{~T}(1) x & 0 \cdot 107 & 0 \cdot 120 \\ \quad y & 0 \cdot 299 & 0 \cdot 326 \\ z & 0.286 & 0 \cdot 248 \\ \mathrm{~T}(2) x & 0 \cdot 390 & 0.410 \\ \mathrm{~T}(1)-\mathrm{T}\left(1^{\prime}\right) & 2 \cdot 76 \AA & 3 \cdot 10 \AA \\ \mathrm{T}(1)-\mathrm{T}(2) & 2 \cdot 80 & 3 \cdot 10 \\ \mathrm{~T}\left(1^{\prime \prime}\right)-\mathrm{T}(2) & 2 \cdot 77 & 3 \cdot 11\end{array}$

\section{Proton positions}

The question whether the protons in ice III are in ordered arrangement, as in ice II (Kamb, 1964), or are disordered, as in ice I (Pauling, 1935; Peterson \& Levy, 1957), is of much importance in relation to physical properties and to the nature of order-promoting interactions in the ice phases. The entropy of ice III in relation to ices I and II indicates that within its stability field ice III is proton-disordered (Kamb, 1964, p. 1446), and disorder is also indicated by the dielectric properties (Wilson, Chan, Davidson \& Whalley, 1965). Whether the protons in the quenched ice III observed here are ordered or disordered is therefore a question of whether or not the disorder is really complete under conditions of stability, and of whether or not ordering takes place within the originally disordered structure upon cooling to $-195^{\circ} \mathrm{C}$, or upon release of pressure.

The ice III structure permits either ordered or disordered proton arrangements with the cell size and symmetry indicated by the diffraction photographs. This is unlike the situation in ices I, Ic, V, VI, and VII, where proton ordering can occur only with a lowering of symmetry and/or an increase in cell size. It is also unlike the situation in ice II, where the symmetry would necessarily be increased if the protons were to go into a disordered arrangement, so that only an ordered arrangement is possible (Kamb, 1964).

A straightforward indication is given by the difference synthesis in Fig. 1, which is unbiased by any assumptions as to the proton positions in ice III. All six possible symmetry-independent proton positions are represented by peaks of height $0 \cdot 2-0 \cdot 4 \mathrm{e} . \AA^{-3}$, averaging about half the $0.6 \mathrm{e} . \AA^{-2}$ commonly found for hydrogen atoms in refined organic structures. A proton-disordered ('half-hydrogen') structure is indicated by this evidence. Statistical fluctuations in the difference density in Fig. 1 (estimated standard deviation $0 \cdot 1$ e. $\AA^{-3}$ ) could to some extent falsify the indications of proton arrangement, and there is one peak of height $0 \cdot 18 \mathrm{e} . \AA^{-3}$ (not shown in Fig. 1) that cannot be attributed to a proton position. However, the two strongest hydrogen peaks, which are least subject to such falsification, lie along the same $O \cdots O$ line $\left[O(1) \cdots O\left(2^{\prime}\right)\right]$, and hence rule out an ordered structure. It seems improbable that random errors would lead consistently to false peaks at all of the positions expected for hydrogen atoms in a disordered structure. The $\mathrm{O}-\mathrm{H}$ distances (Table 5), while somewhat short on the average, are not unreasonable in view of the probable effects of apparent thermal motion, which should be particularly large for a statistical structure under distorted tetrahedral coordination. Most of the $\mathrm{H}-\mathrm{O}-\mathrm{H}$ angles (Table 6) show the expected improvement (toward $109.5^{\circ}$ ) in relation to the corresponding $\mathrm{O} \cdots \mathrm{O} \cdots \mathrm{O}$ angles, but there is a conspicuous exception in the very low $\mathrm{H}-\mathrm{O}-\mathrm{H}$ angle of $74^{\circ}$. This angle involves $H(3)$ and $H(4)$, which are represented by the weakest peaks in Fig. 1 .

The best proton-ordered structure available as an alternative is the structure $D$ discussed earlier (Table 3 ), in which $\mathrm{H}(3)$ and $\mathrm{H}(4)$ are omitted (in addition to $H(8)$, represented by a strong peak in Fig. 1). The residual $R$ and the weighted sum of squares $R_{\mathrm{ws}}^{2}$ for this structure are only slightly larger than for the disordered structure (Table 2). The two structures appear to satisfy the X-ray data almost equally well. A statistical test, based on methods described by Hamilton (1965), indicates that the improvement in the refined $R_{\mathrm{ws}}^{2}$ from 0.0122 to 0.0112 on replacing hydrogen population factors of 1 and 0 in structure $D$ by $\frac{1}{2}$ in the disordered structure is not significant at the $90 \%$ confidence level.

Although the evidence from the difference map and least-squares refinement is weighted in favor of the half-hydrogen model, which would normally be interpreted as a proton-disordered structure, the crystallographic data do not rule out the proton-ordered structure $D$. Three independent pieces of evidence from physical properties, discussed below, suggest that some sort of ordering of the protons in ice III occurs at low temperatures.

\section{Thermodynamic evidence of proton order}

The transition energy $\Delta E$ and entropy $\Delta S$ between ice I and III, determined by Bridgman (1912), are strongly temperature dependent (Table 8). The energy of ice III relative to ice I decreases by $0.18 \mathrm{kcal} . \mathrm{mole}^{-1}$ from $-22^{\circ} \mathrm{C}$ to $-60^{\circ} \mathrm{C}$, suggesting that water molecule orientations less favored energetically in ice III become progressively less abundant at lower temperatures. The entropy of ice III relative to ice I decreases over the same interval by 0.8 e.u., just the amount of 
the configurational entropy of proton disorder (Pauling, 1935). The volume difference $\Delta V$ between ice I and ice III (Table 8 ) increases markedly with decreasing temperature, suggesting that as proton ordering occurs, unfavorable proton relationships in the $\mathrm{H}$ bonds are eliminated, so that the bonds contract. The gradual change in $\Delta E$ and $\Delta S$ with temperature (Table 8) suggests progressive ordering on cooling, as opposed to a sharp ordering transition. Whalley \& Davidson (1965) suggested from the $\Delta V$ data a higherorder transition at about $-40^{\circ} \mathrm{C}$.

Table 8. Data for the ice I-ice III equilibrium curve (Bridgman, 1912)

$\begin{array}{ll}\stackrel{T}{T} & P \\ \left({ }^{\circ} \mathrm{C}\right) & (\mathrm{atm}) \\ -22 \cdot 0 & 2047 \\ -30 & 2087 \\ -34 \cdot 7 & 2100 \\ -40 & 2108 \\ -50 & 2091 \\ -60 & 2049\end{array}$

$\Delta V$
$\left(\mathrm{~cm}^{3} \mathrm{~g}^{-1}\right)$
-0.1818
-0.1919
-0.1963
-0.1992
-0.2023
-0.2049

$\Delta E$
(kcal.mole-1)
0.26
0.24
0.22
$0 \cdot 19$
0.15
0.08

$\Delta S$
(e.u.)
$0 \cdot 37$
$0 \cdot 26$
$0 \cdot 17$
0.05
-0.17
-0.47

This implied temperature-dependent state of partial proton order is a novel feature among the ice structures; its closest parallel is the stress-induced partial proton order proposed to account for the elastic relaxation of ice I (Bass, 1958). The variation of $\Delta V$, $\Delta E$, and $\Delta S$ along the I-III equilibrium curve is quite unlike the near constancy of these quantities along most of the other ice-ice-equilibrium curves. Bridgman (1935, p.605) expressed the opinion that the PVT behavior of ices III and I near the I-III equilibrium curve was markedly different from that expected for 'normal' solids; we are here attributing the abnormalities to the ice III phase.

As a note of caution toward these interpretations, it should be pointed out that the determination by Bridgman (1935) of the ice I-ice III equilibrium curve, for $\mathrm{D}_{2} \mathrm{O}$, showed none of the anomalous behavior in Table 8 for $\mathrm{H}_{2} \mathrm{O}$, and indicated instead a constant entropy increase of 0.2 e.u. from ice I to ice III, down to $-60^{\circ} \mathrm{C}$. On the other hand, Tammann's (1903) measurements on $\mathrm{H}_{2} \mathrm{O}$ were in agreement with Bridgman's (1912) in showing a reversal in slope of the I-III equilibrium curve, which is responsible for the change in sign of $\Delta S$ in Table 8 . We should note that Bridgman's ice VI-ice VII equilibrium line (Bridgman, 1937) showed a marked curvature at lower temperatures (where the reaction becomes sluggish and the equilibrium curve difficult to determine accurately), whereas a redetermination by Brown \& Whalley (1966) showed instead a sharp kink in the otherwise straight curve, just at the temperature at which the ordered phase ice VIII appears. Dielectric measurements on ice III down to $-44^{\circ} \mathrm{C}$ show no obvious hint of either progressive ordering or an order-disorder transition above this temperature (Wilson et al., 1965). These considerations may indicate that any ordering must occur at a temperature below $-60^{\circ} \mathrm{C}$.
A related thermodynamic suggestion of ordering is found in the heats of inversion measured by Bertie, Calvert \& Whalley (1964). The heat of inversion of ice III, in relation to the energy estimated from the $\Delta E$ data of Bridgman, is somewhat low when compared with other ice phases (Table 9).

\begin{tabular}{lcccr}
\multicolumn{5}{c}{ Table 9. Comparison of ice phases } \\
Ice & $\begin{array}{c}\Delta H_{\mathrm{inv}}{ }^{*} \\
\left(\mathrm{kcal}^{\mathrm{mole}} \mathrm{mol}^{-1}\right)\end{array}$ & $\begin{array}{c}E-E_{\mathrm{I}} \dagger \\
(\mathrm{kcal} . \mathrm{mole}\end{array}$ & $\begin{array}{c}\bar{B} \ddagger \\
\left(\AA^{2}\right)\end{array}$ & $g \S$ \\
Ic & 0.03 & - & 1.7 & 3.4 \\
II & $<0.04$ & 0.01 & 1.85 & 0.0 \\
III & 0.10 & 0.24 & 2.5 & 2.7 \\
V & 0.23 & 0.31 & 2.2 & 2.9 \\
VI & 0.32 & 0.41 & 2.2 & 3.4 \\
VIII & 0.59 & 0.66 & - & 0.0
\end{tabular}

* To the heats of inversion (to ice Ic) measured by Bertie, Calvert \& Whalley (1964) has been added the $0.03 \mathrm{kcal}$. mole $^{-1}$ heat of inversion of ice Ic to ice I, based on measurements by McMillan \& Los (1965) and Beaumont, Chihara \& Morrison (1961).

$\dagger$ Energy relative to ice $I$ at atmospheric pressure, estimated by summing the transition $\Delta E$ values measured by Bridgman $(1912,1937)$, averaged along the individual phase boundaries. These values can be expected to approximate the energies of the ice phases when decompressed to atmospheric pressure. Data for ice VIII are from Brown \& Whalley (1966).

$\ddagger$ Average effective isotropic temperature parameter for refined ice structures, at $c a .-175^{\circ} \mathrm{C}$. For ice V and VI, $\bar{B}$ is taken as the average of the principal axes of the thermal motion ellipsoids. For ice II and ice III, $\vec{B}$ is taken as the value obtained on isotropic refinement, averaged over the non-equivalent atoms; for ice III this result is the same as obtained by averaging the principal axes of the anisotropic thermal motion ellipsoids. The $B$ value for ice Ic is based on electron diffraction data of Shimaoka (1960), and is calculated from the quoted Debye temperature of $203^{\circ} \mathrm{K}$ by assuming a specimen temperature of $-175^{\circ} \mathrm{C}$. In all cases the $B$ values are obtained by refinement after inclusion of hydrogen atoms. $\vec{B}$ values for the high-pressure ices are from Kamb (1964), Kamb, Prakash \& Knobler (1967), Table 4 of the present paper, and Kamb \& Prakash (unpublished work), and are subject to an estimated standard deviation of $\pm 0 \cdot 1 \AA^{2}$.

$\S g$ is the Kirkwood correlation factor, derived from the dielectric constant measured under conditions of stability of the individual phases (Wilson et al., 1965). The value listed for ice Ic is actually the value for ice I.

\section{Spectroscopic evidence}

Bertie \& Whalley (1964b) interpret infrared spectra of high pressure ices as indicating proton order in both ice III and ice II at $77^{\circ} \mathrm{K}$. The evidence for order is the resolution of sharp lines in the $\mathrm{OH}$ or OD stretching bands of HDO, and of sharp lines superimposed on the broad librational bands of $\mathrm{H}_{2} \mathrm{O}$ and $\mathrm{D}_{2} \mathrm{O}$. For ice II, the observed resolution of the OD stretching band into four lines is consistent with the four non-equivalent $\mathrm{H}$-bonds in the ordered structure indicated by X-ray data (Kamb, 1964). For ice III only two lines, of unequal strength, are resolved. Any ordered proton arrangement for the ice III structure (in $P 4_{1} 2_{1} 2$ ) involves three non-equivalent bonds in equal numbers. To account for the observed spectrum, one must assume that the OD stretching frequencies for two of these bonds happen to coincide. 
A comparison of structural and spectroscopic data for ice phases is given in Fig. 3. OD stretching frequencies for dilute $\mathrm{HDO}$ in the $\mathrm{H}_{2} \mathrm{O}$ ices are plotted against hydrogen bond lengths, under the assumption that the stretching frequencies in ascending order correlate with bond lengths in ascending order. Where individual frequencies are not resolved, the corresponding bond lengths are averaged. All frequencies were measured at $-196^{\circ} \mathrm{C}$ (Bertie \& Whalley, 1964a,b), except for the frequency for ice I at $0^{\circ} \mathrm{C}$ (reported by Falk \& Ford, 1966). The bond lengths for ice I at $-196^{\circ} \mathrm{C}$ are calculated from the cell data of Brill \& Tippe (1967) assuming the oxygen $z$ parameter to be 0.0620 , as at $-150^{\circ} \mathrm{C}$ (Peterson \& Levy, 1957); for ice $\mathrm{I}$ at $0^{\circ} \mathrm{C}$ they are taken from Lonsdale (1958, Table 3). Bond lengths for ice II are from Kamb (1964), with correction,* and for ice III from the present paper (structure $D$ ). These bond lengths are measured at $-175^{\circ} \mathrm{C}$, but, if the thermal expansion behavior of ice I (Brill \& Tippe, 1967) is applicable to the other ice phases, the changes in bond lengths from $-175^{\circ} \mathrm{C}$ to $-196^{\circ} \mathrm{C}$ are negligible. $\mathrm{OH}$ stretching frequencies for dilute $\mathrm{HDO}$ in the $\mathrm{D}_{2} \mathrm{O}$ ices (Bertie \& Whalley, $1964 a, b$ ) show a very similar pattern to the $\mathrm{OD}$ frequencies of Fig. 3, and the $\mathrm{OH}$ frequency shifts (relative to ice I) correspond closely to the OD shifts multiplied by 1.35 . The choice of OD frequencies for plotting in Fig. 3 (against $\mathrm{OH}$... O bond lengths) was made because the narrower line width of the OD stretching bands allows some lines to be resolved for $\mathrm{OD}$ that are not resolved for $\mathrm{OH}$; cell constants and bond lengths for $\mathrm{H}_{2} \mathrm{O}$ and $\mathrm{D}_{2} \mathrm{O}$ ices differ very little as far as known (Lonsdale, 1958; Kamb \& Prakash, unpublished work), so that Fig. 3 may be regarded to a good approximation as a plot of $\mathrm{OD}$ frequency against $\mathrm{OD} \cdots \mathrm{O}$ bond length.

The points in Fig. 3 for the proton-ordered phase ice II lie closely along a straight line, which shows that structural and spectroscopic data are in agreement under the assumption that the main effect on OD stretching frequency is hydrogen bond length. The relation between frequency and bond length is approximately linear over the range of bond lengths involved. The upward shift in stretching frequencies in ice II as compared with ice I at the same bond lengths presumably reflects effects of bond bending on the frequencies.

Of the two points for ice III in Fig. 3, the lower one corresponds to the stronger peak in the observed spectrum, which is in agreement with the fact that, of the three bond lengths in ice III (Table 5), the lower two are rather closely spaced. Since in ordered structure $D$ these two bond lengths differ by $0.016 \pm 0.007 \AA$,

* Owing to a computational error in deriving the bond lengths from the measured coordinates in ice II, some of the bond lengths given in the original paper (Kamb, 1964) are slightly in error. The correct values (in the notation of that paper) are: $\mathrm{I}-2=2 \cdot 81 \AA, \mathrm{I}-4=2 \cdot 76 \AA$, II $-1=2 \cdot 77 \AA$, II -3 $=2 \cdot 83 \AA$ the failure to resolve the corresponding frequencies, when frequencies corresponding to bond lengths only $0.008 \pm 0.014 \AA$ apart are resolved in ice II, may be attributable to the somewhat larger inherent line width in ice III, but the apparent discrepancy lies within the range of experimental error in the bond lengths and may not be real. While the lower point for ice III in Fig. 3 conforms to the data for ice II, the upper point deviates greatly, and the indicated slope of the frequency versus bond-length relation, $\partial v_{\mathrm{OD}} / \partial d=210$ $\mathrm{cm}^{-1} \AA^{-1}$ (corresponding to $\partial v_{\mathrm{OH}} / \partial d \simeq 280 \mathrm{~cm}^{-1} \AA^{-1}$ ), is much less than the slope $\partial v_{\mathrm{OH}} / \partial d=3000 \mathrm{~cm}^{-1} \AA^{-1}$ assumed by Bertie \& Whalley (1964b) in discussion of spectroscopic effects of proton disorder in the ice phases. The deviation cannot be attributed to a simple effect of bond bending, for three reasons: (1) the $\mathrm{O} \ldots \mathrm{O} \cdots \mathrm{O}$ angles utilized for the $\mathrm{H}-\mathrm{O}-\mathrm{H}$ orientations in structure $D$ (Table 6, angles marked $\dagger$ ) allow all of the protons to lie very nearly on the $0 \cdots O$ centerlines; (2) the measured hydrogen coordinates (Table 3) correspond to departures of only $0 \cdot 09-0 \cdot 13 \AA$ $( \pm 0.08)$ from the centerlines; (3) the bond bending represented by an $\mathrm{O} \cdots \mathrm{O} \cdots \mathrm{O}$ angle of $88^{\circ}$ for one of the water molecule orientations in ice II (as proposed by Kamb in 1967) produces no evident disturbance in the relation between stretching frequency and bond length for ice II in Fig. 3.

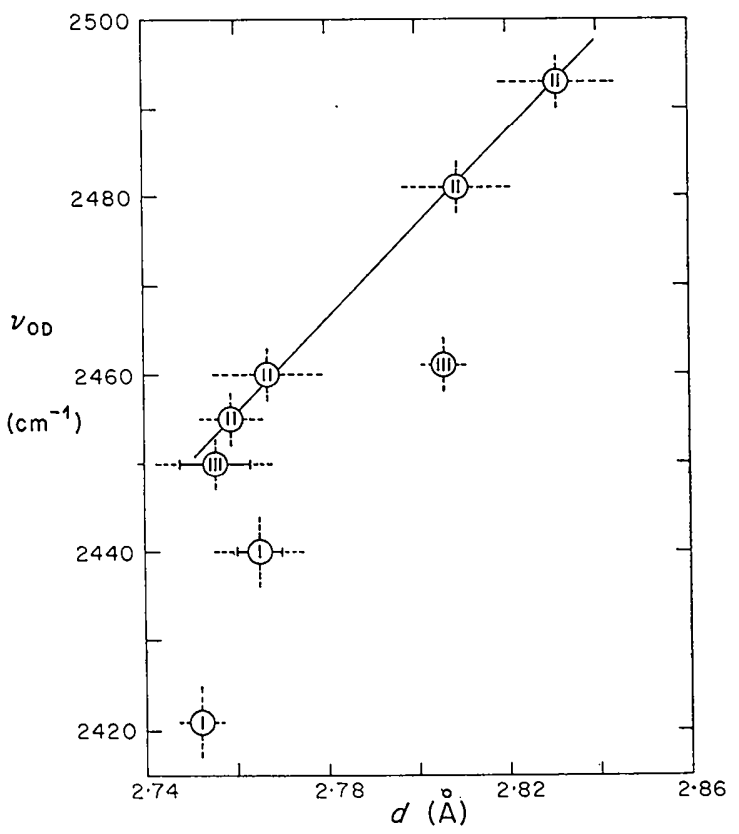

Fig. 3. Correlation of $\mathrm{H}$-bond lengths $d$ and $\mathrm{OD}$ stretching frequencies $v_{O D}$ in ices I, II, and III. Estimated standard deviations in experimental values are shown with dashed lines. Where two bond lengths have been averaged to give the value plotted, the individual lengths are indicated at the ends of a solid line bracketing the plotted point. Sources of data are given in text. 
Except for the unexplained anomaly represented by the position of the upper point for ice III in Fig.3, the spectroscopic data for ice II and ice III can be interpreted consistently in relation to the structures as determined by X-rays, and the spectroscopic evidence for proton order in quenched ice III thus appears as good as for ice II.

Interpretation of the resolved OD stretching bands as indicative of proton order (Bertie \& Whalley, 1964b) is based on the idea that in a disordered structure, the various orientation relationships between $\mathrm{H}$-bonded water molecules will result in a spread of $\mathrm{H}$-bond lengths and a corresponding spread in stretching frequencies. There is at present no direct way to predict what spread of individual H-bond lengths would actually occur in a proton-disordered ice III structure. However, indirect indications are given by the ice II and ice V structures. In ice II, two bonds that would appear equivalent in a hypothetical proton-disordered structure actually differ in length by $0.04 \pm 0.017 \AA$ as a result of the two different bonding relationships that occur in the actual ordered structure; this suggests that a spread in bond lengths of this magnitude could occur in a disordered structure. In ice V, interpreted as a disordered structure (Kamb, Prakash \& Knobler, 1967), there is a pair of (disorder-averaged) bond lengths spaced $0.047 \pm 0.008 \AA$ apart with no intermediates, and yet no corresponding resolution of a pair of lines is found in the infrared spectrum (Bertie \& Whalley, 1964b), implying that bond-length spreads sufficient to fill in this $0.047 \AA$ gap are present. On this basis it seems probable that in a proton-disordered ice III structure, large enough local bond-length variations would occur to prevent resolution of lines corresponding to (averaged) bond lengths spaced 0.030 or 0.043 $\pm 0.007 \AA$ apart (as given respectively by the halfhydrogen or full-hydrogen models of ice III, for the difference between the $\mathrm{O}(1)-\mathrm{O}(2)$ and $\mathrm{O}\left(1^{\prime \prime}\right)-\mathrm{O}(2)$ bond lengths, Table 5).

\section{Structural considerations in relation to proton order}

One feature in the structure of ice III would appear to lead naturally to proton ordering at low temperatures. The abnormally large $\mathrm{O}\left(1^{\prime}\right)-\mathrm{O}(1)-\mathrm{O}\left(2^{\prime}\right)$ bond angle of $143.3^{\circ}$ is unfavorable for $\mathrm{H}-\mathrm{O}-\mathrm{H}$ occupancy, because of the large amount of $\mathrm{H}$-bond bending required for the $1^{\prime}-1-2^{\prime}$ orientation of the water molecule at $\mathrm{O}(1)$. (The notation used here for water molecule orientations at given oxygen sites lists the three oxygen atoms in the $\mathrm{O} \cdots \mathrm{O} \cdots \mathrm{O}$ bond angle toward which the $\mathrm{H}-\mathrm{O}-\mathrm{H}$ angle is presented, the number designations for oxygen being those shown in Fig.3). On the basis of $\mathrm{H}$-bond bending force constants from different sources (Kamb, 1968), the $1^{\prime}-1-2^{\prime}$ orientation should be destabilized by at least $1.3 \mathrm{kcal} . \mathrm{mole}^{-1}$. If no further interactions or cooperative effects were to enter, one could expect a temperature-dependent degree of partial proton order, in which the water molecule at $O(1)$ assumes the orientation $1^{\prime}-1-2^{\prime}$ with decreasing probability at lower temperatures.*

The observable effect, to X-rays, of such a partially ordered but still statistical structure would be a decrease by about one-third in the apparent electron density at the two proton sites near $\mathrm{O}(1)$, along the $\mathrm{O}(1)-\mathrm{O}\left(1^{\prime}\right)$ and $\mathrm{O}(1)-\mathrm{O}\left(2^{\prime}\right)$ bonds. In relation to the estimated standard deviation of the hydrogen population factors $( \pm 0 \cdot 07)$ or of the electron density $( \pm 0 \cdot 1$ e. $\AA^{-3}$ ), such a decrease, amounting to 0.17 in population factor or $0 \cdot 1$ e. $\AA^{-3}$ in electron density, would not be realiably detectable with our X-ray data, which are therefore consistent with a statistical structure of this type.

A partially ordered statistical structure could account for the decrease at low temperature in $\Delta E$ between ice III and ice I, but it could not account for the full extent of the decrease in $\Delta S$ (Table 8). Also, it probably would not explain the resolution of sharp lines in the OD stretching band, because the number of $\mathrm{H}$ bonds non-equivalent as to bonded-neighbor relationships would remain large (45).

A way to reconcile these features with the halfhydrogen model favored by the X-ray data would be to assume that the X-ray sample of ice III was quenched rapidly enough to 'freeze in' a statistical structure, whereas the samples used for infrared spectroscopy by Bertie \& Whalley $(1964 a, b)$ were cooled slowly enough to allow a long-range ordering transition to occur. But this rationalization is unlikely. The infrared samples were made and quenched in apparatus very similar to ours (so that the cooling rate on quenching will be similar), and they were quenched from the same or a higher temperature (Bertie, Calvert \& Whalley, 1963, p. 1647). Moreover, the dielectric relaxation time for ice III is only about $2 \mathrm{msec}$ at $-80^{\circ} \mathrm{C}$ (based on extrapolation of the measurements of Wilson et al., 1965), so that an ordering transition at or above this temperature would run rapidly in relation to the quenching time of several seconds.

* The destabilization energy of $1.3 \mathrm{kcal}$.mole 1 for the $1^{\prime}-1-2^{\prime}$ orientation corresponds to an energy decrease of $0.13 \mathrm{kcal} . \mathrm{mole}^{-1}$ for ice III in eliminating this orientation, which compares favorably with the energy decrease of $0.18 \mathrm{kcal}$ suggested by the $\Delta E$ data in Table 8 , and with the difference 0.14 kcal.mole ${ }^{-1}$ between $E-E_{I}$ and $\Delta H_{\mathrm{inv}}$ in Table 9. However, if the destabilization energy were actually as large as $1.3 \mathrm{kcal}$.mole ${ }^{-1}$, then this orientation would already be practically absent in ice III within its stability field, since $k T$ at $-25^{\circ} \mathrm{C}$ is only $0.5 \mathrm{kcal}$.mole $\mathrm{e}^{-1}$. The decrease in configurational entropy of ice III upon partially ordering so as to eliminate the $1^{\prime}-1-2^{\prime}$ orientation is 0.18 e.u., computed by Pauling's (1935) method. For an ordering energy of $0.13 \mathrm{kcal}$.mole ${ }^{-1}$, an ordering transition would be expected at $\sim 650^{\circ} \mathrm{C}$. An indication that some water molecule orientations are avoided in ice III within its stability field is given by the comparatively low value of the dielectric constant in relation to ice I, as assessed by the Kirkwood correlation factor $g$ (Table 9). If, indeed, the $1^{\prime}-1-2^{\prime}$ orientation is avoided at $-22^{\circ} \mathrm{C}$, then the energy and entropy changes indicated by the data in Table 8 may reflect progressive avoidance (with falling temperature) of some other angle or angles, such as the $1-2-1^{\mathbf{v}}$ angle of $128^{\circ}$. 
Alternatively, one may postulate that at low temperatures the ordering is not quite complete, in the sense that more than one type of proton arrangement remains present, such as to give a half-hydrogen structure when averaged over the crystal. Or one may postulate that ordering takes place at a lower symmetry, but with effects too slight to cause violation of the $4_{1}$ or $2_{1}$ extinction rules at the level of detection reached in our search for such violations $\left(F_{0} \simeq 2 \cdot 0\right)$. These postulates would be compatible with the resolution of the OD stretching band into two lines, if the local variations in bond lengths equivalent under $P 4_{1} 2_{1} 2$ were distinctly smaller than about $0.05 \AA$.

Ice III shows the largest apparent thermal motions of any of the refined ice structures (Table 9). The fact that the X-ray data for all of the structures in Table 9 except ice Ic were obtained under the same experimental conditions makes it likely that the differences in $\bar{B}$ among them are significant. It is reasonable to assume that there is a relationship among the $\bar{B}$ values in Table 9 analogous to that noted for ordered and disordered aluminosilicates (Bragg \& Claringbull, 1966, p.326; Meagher \& Gibbs, 1967), namely, that the ordered structures have lower apparent thermal motions. The exception in the case of ice Ic (for which there is some uncertainty anyway in the appropriate $\bar{B}$ value*) can be explained on the grounds that in this structure, the coordination of the water molecules is so nearly perfect that only very slight oxygen displacements will result from a change from one watermolecule orientation to another. A further suggestion of anomalous oxygen displacements in ice III is the relatively large anisotropy of the apparent thermal motions ( $B_{i}$ values in Table 4). The anisotropy for $\mathrm{O}(2)$ is as large as that for the oxygen atom in ice II when refined in the pseudo-space-group $R \overline{3} c$ that ignores the displacements attendant upon proton ordering (Kamb, Prakash \& Knobler, 1967, Table 7). The relatively large apparent thermal motions and anisotropies in ice III thus lend support to a statistical or incompletely ordered structure, or to a structure ordered at lower symmetry.

The alternative model, proton-ordered structure $D$, has the favorable feature that it utilizes for water molecule orientations the best $0 \cdots \mathrm{O} \cdots \mathrm{O}$ angles available for an ordered structure in $P 4_{1} 2_{1} 2\left(1^{\prime \prime \prime}-1-2^{\prime}\right.$ and $1-2-1^{\text {iv }}$, marked $\dagger$ in Table 6 ), that is, the angles closest to the $104.5^{\circ} \mathrm{H}-\mathrm{O}-\mathrm{H}$ angle of the free water molecule. [The good 1-2-1" angle cannot be used because a molecule in this orientation would violate the twofold axis through $\mathrm{O}(2)$.] Perhaps this favorable feature is responsible for the fact that, even if the struc-

\footnotetext{
* The $\bar{B}$ value for ice Ic in Table 9 is sensitive to the crystal temperature, which thermocouple measurements indicate to be about $-175^{\circ} \mathrm{C}$ in our apparatus. If the temperature were instead as high as $-150^{\circ} \mathrm{C}$, the value of $\bar{B}$ for ice Ic would rise to $2 \cdot 0 \AA^{2}$. Note, however, the anomalously low value $\bar{B}=$ $1.5 \AA^{2}$ for $\mathrm{D}_{2} \mathrm{O}$ ice $\mathrm{I}$ at $-150^{\circ} \mathrm{C}$, obtained from neutron diffraction by Peterson \& Levy (1957).
}

ture is actually statistical, the ordered model $D$ is able nevertheless to give a good account of the X-ray data.

Note added in proof: Since the foregoing was written, a single-crystal neutron diffraction study of $\mathrm{D}_{2} \mathrm{O}$ ice III carried out by W.C. Hamilton, B. Kamb, S. J.LaPlaca, and A.Prakash has shown that ice III at $-165^{\circ} \mathrm{C}$ and $1 \mathrm{~atm}$ is deuteron-ordered in space group $P 4_{1} 2{ }_{1} 2$, with the deuteron arrangement $D$ given above. Also, Whalley, Heath \& Davidson (1968) have reported dielectric evidence for an ordering transition in ice III that takes place gradually over the temperature interval from about -65 to $-110^{\circ} \mathrm{C}$, and Kell \& Whalley (1968) report an ice I-ice III equilibrium curve that disagrees with Bridgman's (1912) curve for $\mathrm{H}_{2} \mathrm{O}$ but resembles his (1935) for $\mathrm{D}_{2} \mathrm{O}$. The basic features of the ordering transition indicated by the recent data appear similar to those suggested by Bridgman's (1912) data in Table 8 above, except that the temperature interval of the transition lies lower. With this difference, our discussions, above, of proton ordering from the thermodynamic and structural points of view remain relevant.

The crystallographic calculations were carried out with use of the CRYRM (7094) program written by R.E.Marsh and collaborators. We are indebted to Mrs Jean Stroll Westphal for writing program revisions to improve the handling of space group $P 4_{1} 2_{1} 2$. This work was supported by a grant from the National Science Foundation.

\section{References}

Bass, R. (1958). Z. Physik, 153, 16.

Beaumont, R. H., ChiHara, H. \& Morrison, J. A. (1961). J. Chem. Phys. 34, 1456.

Bertie, J. E., Calvert, L. \& Whalley, E. (1963). J. Chem. Phys. 38, 840.

Bertie, J. E., Calvert, L. \& Whalley, E. (1964). Canad. J. Chem. 42, 1373.

Bertie, J. E. \& Whalley, E. (1964a). J. Chem. Phys. 40, 1637.

Bertie, J. E. \& Whalley, E. (1964b). J. Chem. Phys. 40, 1649.

BragG, L. \& Claringbull, G. F. (1965). Crystal Structure of Minerals. Ithaca: Cornell Univ. Press.

Bridgman, P. W. (1912). Proc. Amer. Acad. 47, 441

Bridgman, P. W. (1935). J. Chem. Phys. 3, 597.

Bridgman, P. W. (1937). J. Chem. Phys. 5, 964.

Brill, R. \& TIPPE, A. (1967). Acta Cryst. 23, 343.

Brown, A. J. \& Whalley, E. (1966). J. Chem. Phys. 45, 4360 .

FALK, M. \& Ford, T. A. (1966). Canad. J. Chem. 44, 1699. Hamilton, W. C. (1965). Acta Cryst. 18, 502.

International Tables for X-ray Crystallography (1959). Vol. II, Birmingham: Kynoch Press.

KAMB, B. (1964). Acta Cryst. 17, 1437.

KАMB, B. (1965a). Science, 148, 232.

KAMB, B. (1965b). Science, 150, 205.

KAMB, B. (1968). In Structural Chemistry and Molecular Biology. Edited by N. Davidson \& A. Rich, San Francisco: Freeman.

KaMB, B. \& DatTA, S. K. (1960). Nature, Lond. 187, 140. 
Kamb, B. \& Davis, B. L. (1964). Proc. Nat. Acad. Sci. Wash. 52, 1433.

Kamb, B., Prakash, A. \& Knobler, C. (1967). Acta Cryst. 22, 706 .

Kell, G. S. \& Whalley, E. (1968). J. Chem. Phys. 48, 2359.

Lonsdale, K. (1958). Proc. Roy. Soc. A247, 424.

McFarlan, R. L. (1936a). J. Chem. Phys. 4, 60.

McFarlan, R. L. (1936b). J. Chem. Phys. 4, 253.

McMillan, J. A. \& Los, S. C. (1965). Nature, Lond. 206, 806.

Meagher, A. P. \& Gibbs, G. V. (1967). Program, G.S.A. Ann. Mtg., New Orleans, p. 146.

Pauling, L. (1935). J. Amer. Chem. Soc. 57, 2680.

Peterson, S. W. \& Levy, H. A. (1957). Acta Cryst. 10, 70.
Powell, R. W. (1958). Advanc. Phys. 7, 276.

Shimaoka, K. (1960). J. Phys. Soc. Japan, 15, 106.

Shropshire, J., Keat, P. P. \& Vaughan, P. A. (1959). Z. Kristallogr. 112, 409.

Stewart, R. F., Davidson, E. R. \& Simpson, W. T. (1965). J. Chem. Phys. 42, 3175.

Tammann, G. (1903). Kristallisieren und Schmelzen. Leipzig: Barth.

Whalley, E. \& Davidson, D. W. (1965). J. Chem. Phys. 43, 2148.

Whalley, E., Heath, J. B. R. \& Davidson, D. W. (1968). J. Chem. Phys. 48, 2362.

Wilson, G. J., Chan, R. K., Davidson, D. W. \& WhalLeY, E. (1965). J. Chem. Phys. 43, 2384.

Acta Cryst. (1968). B24, 1327

\title{
The Structure of Orthorhombic $\mathrm{Y}_{2} \mathrm{TiO}_{5}$, an Example of Mixed Seven- and Fivefold Coordination
}

\author{
By W.G. Mumme ANd A.D. WadsLeY \\ Division of Mineral Chemistry, CSIRO, Melbourne, Australia
}

(Received 4 December 1967)

\begin{abstract}
Crystals of $\mathrm{Y}_{2} \mathrm{TiO}_{5}$, grown by heating the composition $\mathrm{NaYTiO}_{4}$ at $1500^{\circ} \mathrm{C}$ in air, have the unit-cell dimensions $a=10 \cdot 35, b=3 \cdot 70, c=11 \cdot 25 \AA$, space group Pnma, $Z=4$. The structure was deduced from the Patterson function and refined by three-dimensional Fourier and least-squares methods. The two independent yttrium ions are both in sevenfold coordination, with oxygen atoms forming irregular trigonal prisms capped through one rectangular face. These polyhedra unite by edge-sharing into groups of four extending infinitely in the direction of the short $b$ axis. The groups are held together by the titanium ions which are five-coordinated, with four oxygen ligands from one group and one from the next at the corners of a square pyramid. A number of rare-earth titanates with the same stoichiometry are isomorphous with $\mathrm{Y}_{2} \mathrm{TiO}_{5}$. The relationships to the $B$-type rare-earth oxide, to $\mathrm{YO}(\mathrm{OH})$ and to $\mathrm{Sr}_{2} \mathrm{PbO}_{4}$ structure types are discussed.
\end{abstract}

\section{Introduction}

The mixed-metal oxycompounds formed at high temperature between $\mathrm{Ti}$ or $\mathrm{Zr}$ and the rare earths were summarized recently by Collongues, Queyroux, Perez y Jorba \& Gilles (1965). They reported a number of cubic phases $A_{2} B_{2} \mathrm{O}_{7}$ ( $A$ trivalent, $B$ quadrivalent) with the pyrochlore structure, a rhombohedral group $A_{4} B_{3} \mathrm{O}_{12}$ related to $\mathrm{UY}_{6} \mathrm{O}_{12}$ (Bartram, 1966) and to $\mathrm{Sc}_{4} \mathrm{Zr}_{3} \mathrm{O}_{12}$ (Thornber, Bevan \& Graham, 1968), as well as a third family $A_{2} B_{5}$ existing in both low- and high-temperature modifications. Each of the powder diffraction patterns of low-temperature $\mathrm{Y}_{2} \mathrm{TiO}_{5}, \mathrm{Dy}_{2} \mathrm{TiO}_{5}$ and $\mathrm{Gd}_{2} \mathrm{TiO}_{5}$ was indexed in terms of a monoclinic superlattice $a \simeq 3 a^{\prime}, b \simeq a^{\prime}, c \simeq 3 a^{\prime}, \beta=90-\delta$, originating from a fluorite-type sub-cell of side $a^{\prime}$, and conforming to the notion of a phase intermediate in structure and composition between fluorite-type (stoichiometry $B_{2}$ ) and $C$-type rare-earth oxide $\left(A_{2} \mathrm{O}_{3}\right)$, both of which are cubic.

We now wish to report that a well-crystallized product, formed as one of the thermal decomposition products of $\mathrm{NaYTiO}_{4}$, appears to be identical with the low-temperature form of $\mathrm{Y}_{2} \mathrm{TiO}_{5}$. This phase was overlooked by Ault \& Welch (1966) in their appraisal of the $\mathrm{Y}_{2} \mathrm{O}_{3}-\mathrm{TiO}_{2}$ system. The symmetry and unit-cell dimensions are not those given by Collongues et al. (1965), however, and the structure determination relates it more to the $B$ (monoclinic) rare-earth oxides than to the $C$ (cubic) form.

\section{Experimental}

$\mathrm{NaYTiO}_{4}$, which is readily prepared by solid-state reaction between $\mathrm{Y}_{2} \mathrm{O}_{3}, \mathrm{TiO}_{2}$ and sodium oxalate at $1300^{\circ} \mathrm{C}$ in a sealed system, is related to a number of titanates with the $\mathrm{K}_{2} \mathrm{NiF}_{4}$ structure (Mumme, Reid \& Wadsley, 1967). It decomposes on heating in air at $1500^{\circ} \mathrm{C}$ into a heterogeneous product containing a number of small clear colourless needle-like crystals, which proved from this structure analysis to have the composition $\mathrm{Y}_{2} \mathrm{TiO}_{5}$. The crystallographic constants in Table 1 were determined from the separation of the $\alpha_{1}-\alpha_{2}$ doublet for a number of spots in the back-reflex- 